\title{
Soil Bacterial Community Was Changed after Brassicaceous Seed Meal Application for Suppression of Fusarium Wilt on Pepper
}

\author{
Gaidi Ren ${ }^{1,2,3}$, Yan Ma1,2,3*, Dejie Guo ${ }^{1,2,3}$, Terry J. Gentry ${ }^{4}$, Ping $\mathrm{Hu}^{4}$, \\ Elizabeth A. Pierson ${ }^{5}$ and Mengmeng $\mathrm{Gu}^{5}$
}

${ }^{1}$ Institute of Agricultural Resources and Environment, Jiangsu Academy of Agricultural Sciences, Nanjing, China, ${ }^{2}$ Key Laboratory of Agro-Environment in Downstream of Yangtze Plain, Ministry of Agriculture, Nanjing, China, ${ }^{3}$ Key Lab of Food Quality and Safety of Jiangsu Province-State Key Laboratory Breeding Base, Nanjing, China, ${ }^{4}$ Department of Soil and Crop Sciences, Texas A\&M University, College Station, TX, United States, ${ }^{5}$ Department of Horticultural Sciences, Texas A\&M University, College Station, TX, United States

Application of Brassicaceous seed meal (BSM) is a promising biologically based disease-control practice but BSM could directly and indirectly also affect the nontarget bacterial communities, including the beneficial populations. Understanding the bacterial response to BSM at the community level is of great significance for directing

OPEN ACCESS

Edited by:

Gary M. King,

Louisiana State University,

United States

Reviewed by:

Anu Mikkonen,

University of Jyväskylä, Finland

Matthew G. Bakker,

Agricultural Research Service (USDA),

United States

*Correspondence:

Yan Ma

myjaas@sina.com

Specialty section:

This article was submitted to

Terrestrial Microbiology,

a section of the journal

Frontiers in Microbiology

Received: 14 October 2017

Accepted: 26 January 2018

Published: 13 February 2018

Citation:

Ren G, Ma Y, Guo D, Gentry TJ, Hu P, Pierson EA and Gu M (2018)

Soil Bacterial Community Was

Changed after Brassicaceous Seed Meal Application for Suppression of Fusarium Wilt on Pepper.

Front. Microbiol. 9:185.

doi: 10.3389/fmicb.2018.00185 plant disease management through the manipulation of resident bacterial communities. Fusarium wilt is a devastating disease on pepper. However, little is known about the response of bacterial communities, especially the rhizosphere bacterial community, to BSM application to soil heavily infested with Fusarium wilt pathogen and cropped with peppers. In this study, a 25-day microcosm incubation of a natural Fusarium wilt pathogen-infested soil supplemented with three BSMs, i.e., Camelina sativa 'Crantz' (CAME), Brassica juncea 'Pacific Gold' (PG), and a mixture of PG and Sinapis alba cv. 'IdaGold' (IG) (PG+IG, 1:1 ratio), was performed. Then, a further 35-day pot experiment was established with pepper plants growing in the BSM treated soils. The changes in the bacterial community in the soil after 25 days of incubation and changes in the rhizosphere after an additional 35 days of pepper growth were investigated by 454 pyrosequencing technique. The results show that the application of PG and PG+IG reduced the disease index by $100 \%$ and $72.8 \%$, respectively, after 35 days of pepper growth, while the application of CAME did not have an evident suppressive effect. All BSM treatments altered the bacterial community structure and decreased the bacterial richness and diversity after 25 days of incubation, although this effect was weakened after an additional 35 days of pepper growth. At the phylum/class and the genus levels, the changes in specific bacterial populations resulting from the $P G$ and $P G+I G$ treatments, especially the significant increase in Actinobacteria-affiliated Streptomyces and an unclassified genus and the significant decrease in Chloroflexi, were suspected to be one of the microbial mechanisms involved in PG-containing BSM-induced disease suppression. This study is helpful for our understanding of the mechanisms that lead to contrasting plant disease severity after the addition of different BSMs.

Keywords: sustainable agricultural systems, Brassicaceous seed meal, Fusarium wilt, bacterial community, 454 pyrosequencing 


\section{INTRODUCTION}

Growth in sustainable agricultural production systems has generated unprecedented demand for environmentally friendly plant disease control strategies. One promising practice is the utilization of organic amendments, a biologically based protocol, for the control of soil-borne plant pathogens. Plants from the family Brassicaceae are usually used as a soil amendment because of their ability to control disease (Lazzeri et al., 2003; Mazzola and Mullinix, 2005; Larkin and Griffin, 2007; Mazzola and Brown, 2010). The mechanism of disease control has been attributed to allelopathy, which is defined as the inhibitory effect of a plant or microorganism (donor) on others (receivers) through the chemicals released from the donor to the environment (Kobayashi, 2004; Hoagland et al., 2008), for example, the glucosinolates within Brassicaceae. Glucosinolates are present in every Brassicaceous plant part but are most concentrated in the seed (Borek and Morra, 2005). Following the incorporation of Brassicaceous seed meal (BSM) residues in soil, glucosinolates could be hydrolyzed into a variety of biocidal products, such as isothiocyanates, nitriles, and ionic thiocyanate $\left(\mathrm{SCN}^{-}\right)$, with isothiocyanates being most toxic (Brown and Morra, 1997; Morra and Kirkegaard, 2002). Isothiocyanates have been shown to be highly active in inhibiting a variety of soil-borne plant pathogens, such as Colletotrichum coccodes, Rhizoctonia solani, Helminthosporium solani (Taylor et al., 2014), Phymatotrichopsis omnivora (Duggar) Hennebert (Hu et al., 2011), and Aphanomyces euteiches f. sp. pisi (Smolinska et al., 1997).

Brassicaceous plants and BSM residue application have become important tools for disease suppression due to their ability to control unwanted microbial pathogens. However, in the natural environment, rather than living alone, pathogens co-exist/co-live with a diverse microbial community. Non-target microorganisms may also be affected directly or indirectly. In the case of direct impact, the antimicrobial activity of the glucosinolate hydrolysis product is not specific in its mode of action (Scott and Knudsen, 1999), and it is possible that the application of Brassicaceous plant material may adversely affect non-target microorganisms and result in changes in the composition of the non-target microbial community, including those that may be of benefit to the plant or that may play prominent roles in disease suppression. In terms of indirect influence, some non-target microorganisms could compete with the pathogen for space and resource (Lemanceau and Alabouvette, 1993). Once the pathogen is suppressed due to the incorporation of Brassicaceous materials, the non-target microbial microorganisms, including the microbial species that are beneficial for plant growth, may obtain more space and resources, leading to rapid proliferation. Therefore, plant disease control not only indicates pathogen suppression but also implies changes in resource/space distribution and, hence, changes in microbial communities. Understanding the changes in nontarget microbial community is important for the ecological assessment of the effect of Brassicaceous plants on soil ecosystems from the viewpoint of microbial ecology. Furthermore, increased understanding is a prerequisite for directing the management of soil-born plant disease through the manipulation of resident microbial communities.

A few studies have been reported on the influence of Brassicaceous plants and BSM residues on the biomass of total bacteria, total fungi, actinomycetes, Gram-negative bacteria, or some specific microbial species, including fluorescent Pseudomonas spp., Streptomyces spp., and Pythium spp. (Scott and Knudsen, 1999; Cohen et al., 2005), in soil through traditional culture-dependent methods. Other authors have documented the influence of isothiocyanates or Brassicaceae materials on the overall bacterial or eukaryotic community structure in soil by means of molecular techniques, such as terminal restriction fragment length polymorphism (T-RFLP), denaturing gradient gel electrophoresis (DGGE) (Ibekwe et al., 2001; Rumberger and Marschner, 2003), and phospholipid fatty acid (PLFA) analysis (Ibekwe et al., 2001; Omirou et al., 2011). However, due to the relatively low resolution of these techniques, the soil microbial diversity is far from being understood. Nextgeneration sequencing could provide not only unprecedented levels of sequence reads to cover and resolve the microbial species (Huse et al., 2008; Hollister et al., 2010), but also relatively finer taxonomic classification information. However, a very limited number of authors have used this method to characterize the soil bacterial and fungal communities after the application of Brassicaceous plant material (Hollister et al., 2013) or isothiocyanates ( $\mathrm{Hu}$ et al., 2015) in their laboratory microcosm-based (i.e., soil incubation only, without plant and disease assays) studies. Under the condition of plant growth, only one study has used the pyrosequencing technique coupled with a pot-based experiment to depict soil fungal communities under different disease-incidence levels resulting from amendment of the soil with BSM residues (Ma et al., 2015).

Fusarium wilt, caused by the soil-borne fungus Fusarium oxysporum, is one of the most serious diseases for a series of plants (Yu et al., 2011; Mowlick et al., 2013; Zhao et al., 2014; LaMondia, 2015; Miyatake et al., 2016; Shi et al., 2016). Because of the ability of this wilt pathogen to colonize the roots of a number of weeds and to produce resistant spore structures, it can persist in the soil indefinitely (Yu et al., 2011) and is hence a great threat not only to the quality and quantity of host crops but also to the sustainability of soil ecosystems. Some studies have demonstrated the soil bacterial community responses after the application of Brassicaceous biomass for the purpose of controlling Fusarium wilt on spinach (Mowlick et al., 2013) and the soil fungal community responses after BSM residue amendment for the purpose of controlling Fusarium wilt on pepper (Ma et al., 2015). However, little is known about the response of soil bacterial communities, especially the rhizosphere bacterial community, to Brassicaceous biomass amendment under the condition that the pepper plant was infected by Fusarium wilt pathogen.

In this study, 25-day microcosm incubation of a natural Fusarium wilt pathogen-infested soil supplemented with different BSMs was performed. With pepper plants growing in these BSM-treated soils, a 35-day disease assay was further established based on pot experiments. The changes in the bacterial community in the soil after 25 days of incubation and changes in the rhizosphere after an additional 35 days of 
pepper growth were investigated using 454 pyrosequencing. The objectives of this study were to (1) examine the effects of different BSMs on the bacterial communities and (2) understand the possible relationship between the bacterial community changes resulting from BSM application and Fusarium wilt on pepper.

\section{MATERIALS AND METHODS}

\section{Soil and Seed Meals}

The soil used in this study was collected from the topsoil $(0-20 \mathrm{~cm})$ of a commercial chili pepper field in Weslaco, Texas, United States, where Fusarium wilt was a consistent and serious problem and where no seed meal amendments were used previously. This soil had a sandy loam texture (sand 69\%, silt 14\%, and clay $17 \%$ ) with $\mathrm{pH} 8.2$. The nutrient content of this soil was as follows (Ma et al., 2015): $0.72 \%$ organic matter, $10 \mathrm{mg} \mathrm{g}^{-1}$ nitrate$\mathrm{N}, 125 \mathrm{mg} \mathrm{g}^{-1} \mathrm{P}$, and $277 \mathrm{mg} \mathrm{g}^{-1} \mathrm{~K}$. The soil was passed through a 5-mm mesh before use.

Three types of defatted BSMs, including seed meal of Camelina sativa cv. 'Crantz', provided by Dr. Terry Gentry from Texas A\&M University, United States; seed meal of Brassica juncea cv. 'Pacific Gold,' provided by Farm Fuel Inc., Freedom, CA, United States; and seed meal of Sinapis alba cv. 'IdaGold,' provided by Farm Fuel Inc., Freedom, CA, United States, were used in this study, and these three seed meals are hereinafter called CAME, PG, and IG, respectively. The content and composition of glucosinolate and the content of $\mathrm{N}, \mathrm{P}$, and $\mathrm{K}$ in these seed meals have been shown previously (Ma et al., 2015). Specifically, PG contained $164 \mu \mathrm{mol} \mathrm{g}^{-1}$ of glucosinolate, with $99 \%$ being 2-propenyl (allyl) glucosinolate; IG contained $195 \mu \mathrm{mol} \mathrm{g}^{-1}$ of glucosinolate, with $97 \%$ being p-hydroxylbenzyl glucosinolate; and CAME contained $23.5 \mu \mathrm{mol}$ $\mathrm{g}^{-1}$ of glucosinolate, with $51.9 \%$ being 10 -methyl-sulfinyl-decylglucosinolate, $30.2 \%$ being 11-methyl-sulfinyl-decyl and $17.9 \%$ being 9-methyl-sulfinyl-decyl glucosinolate. The $\mathrm{N}$ content was 5.9\% in CAME, $6.1 \%$ in PG, and $6.2 \%$ in IG; the P content was $1.01 \%$ in CAME, $1.2 \%$ in PG, and $1.18 \%$ in IG; and the K content was $1.45 \%$ in CAME, $1.5 \%$ in PG, and $1.37 \%$ in IG. These BSMs were sieved through a $1-\mathrm{mm}$ metal mesh before use.

\section{Soil Incubation and Pot Experiment}

Three BSMs, CAME, PG, or a mixture of PG and IG (PG:IG $(\mathrm{w} / \mathrm{w})=1: 1)$, were prepared. This preparation resulted in the establishment of three levels of 2-propenyl (allyl) glucosinolate in these seed meals: $0 \mu \mathrm{mol} \mathrm{g}{ }^{-1}$ in CAME, $164 \mu \mathrm{mol} \mathrm{g}^{-1}$ in PG, and $84 \mu \mathrm{mol} \mathrm{g}^{-1}$ in PG+IG. Then, these seed meals were added separately at an application rate of $0.34 \%$ (w/w, equivalent to $6000 \mathrm{~kg} \mathrm{ha}^{-1}$ ) and mixed thoroughly with the soil. The soil that was amended with no seed meal was used as a control (CK). To bring the $\mathrm{N}, \mathrm{P}$, and $\mathrm{K}$ content onto a common scale, urea (46-0-0) and compound fertilizer (0-15-15) were added to the CK treatment so that the nutrition level was consistent across all treatments. Soil moisture was then adjusted to approximately $70 \%$ of the SWHC (soil water holding capacity) by adding sterilized water. The soil from each treatment was put into three Ziploc ${ }^{\circledR}$ plastic bags, with $7.5 \mathrm{~kg}$ soil in each bag. The bags were left open and incubated at room temperature (approximately $24^{\circ} \mathrm{C}$ ) for 25 days. During the incubation period, sterile water was replenished every 2 days to maintain stable soil moisture based on the weight loss. At the end of the incubation period, $10 \mathrm{~g}$ soil was collected for DNA extraction after the entire soil in each bag was mixed thoroughly. These incubated soil samples hereinafter are referred to as the pre-planting soil samples.

After collecting pre-planting soil samples, the rest of the soil from each bag was divided into six subsamples of equal weight and then put into six pots. Pepper seedlings (Capsicum annuum 'Ben Villalon', 4-leaf stage) were transplanted into the pots at a density of two plants pot ${ }^{-1}$. All the plants grown in these six pots were classified as a replicate group within a treatment. The disease severity of each replicate group was measured at days $7,15,25$, and 35 after transplanting. The disease severity of pepper was ranked into five levels according to a previous method (Ma et al., 2015): 1, healthy; 2, 1/4 leaves turned yellow and fell off; 3, 1/3 leaves turned yellow and fell off; 4, 1/2 leaves turned yellow and fell off; and 5, dead. The disease index was then calculated according to the formula: $\Sigma$ (number of diseased plants $\times$ corresponding level $) \div$ total number of investigated plants $\times 100$. At the end of the pot experiment (35 days after transplanting), rhizosphere soil from each treatment was sampled from three replicate groups for DNA extraction. These samples hereinafter are referred to as the post-planting soil samples. All the pot experiments were conducted in the greenhouse of the Horticulture Department of Texas A\&M University.

\section{Pathogen Characterization}

Junctions at $1 \mathrm{~cm}$ length between the diseased and healthy tissue on stems of the wilted plants were surface-sterilized and incubated on potato-dextrose agar (PDA) containing $50 \mu \mathrm{g}$ $\mathrm{mL}^{-1}$ rifampicin. When mycelium appeared around the stem, they were further cultured on PDA medium and were identified based on microscopic observation of biological characteristics. Fusarium spp. was the only fungus based on the microscopic observation results. To follow Koch's postulates, this isolate was inoculated in sterilized soil where healthy pepper plants were grown. Compared to the plants in the uninoculated soil, plants in the Fusarium-inoculated soil developed the same wilt symptoms. This result further confirmed that the isolated Fusarium spp. was the only pathogen.

\section{DNA Extraction}

Total genomic DNA was extracted from $10 \mathrm{~g}$ pre-planting soil samples and post-planting soil samples collected after 25 days of incubation and after 35 days of pepper plant growth, respectively, using a PowerSoil DNA Isolation Kit (Mo Bio Laboratories, Inc., Carlsbad, CA, United States) following the manufacturer's instructions. Extracted DNA was purified using an Illustra MicroSpin S-400HR Column (GE Healthcare Bio-Sciences Corp., Piscataway, NJ, United States). The quality of the purified DNA was examined by electrophoresis in a $0.8 \%$ agarose gel. DNA quantity and purity were then determined with a Nanodrop ND-1000 spectrophotometer (NanoDrop Technologies Inc., Wilmington, Delaware, United States). All DNA samples were stored at $-20^{\circ} \mathrm{C}$ until use. 


\section{Real-Time Quantitative PCR}

The real-time quantitative PCR technique was applied to quantify the bacterial 16S rRNA gene on a Rotor-Gene 6000 series thermal cycler (Qiagen, Valencia, CA, United States). The forward and reverse primers used were Eub338 (5' - ACT CCT ACG GGA GGC AGC AG-3') and Eub518 (5'-ATT ACC GCG GCT GCT GG-3'), respectively (Fierer et al., 2005). The standard curve for the bacterial $16 \mathrm{~S}$ rRNA gene was generated via 10 -fold serial dilution of plasmid DNA harboring the target gene. The reaction mixture $(15 \mu \mathrm{L})$ contained $6.75 \mu \mathrm{L}$ Real Master Mix with $20 \times$ SYBR solution (5 Prime, Inc., Gaithersburg, MD, United States), $0.5 \mu \mathrm{L}$ each primer $(10 \mu \mathrm{M}), 1.5 \mu \mathrm{L}$ BSA

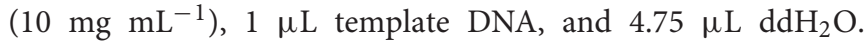
The thermocycling steps were as follows (Fierer et al., 2005): denaturing at $95^{\circ} \mathrm{C}$ for $15 \mathrm{~min}$; followed by 40 cycles of $1 \mathrm{~min}$ at $95^{\circ} \mathrm{C}, 30 \mathrm{~s}$ at $53^{\circ} \mathrm{C}$, and $1 \mathrm{~min}$ at $72^{\circ} \mathrm{C}$; and $30 \mathrm{~s}$ with a plate read. The negative controls with water as the template instead of soil DNA were always run when the real-time quantitative PCR for soil samples was carried out. Real-time quantitative PCR was performed with three technical replications for each DNA sample.

\section{Pyrosequencing and Data Analysis}

For each soil DNA, the $16 \mathrm{~S}$ universal bacterial primer set $27 \mathrm{~F}$ (5'AGR GTT TGA TCM TGG CTC AG-3') and 519R (5'-GTN TTA CNG CGG CKG CTG-3') was used for amplifying the $\sim 500 \mathrm{bp}$ region of $16 \mathrm{~S}$ rRNA genes. To resolve different samples, an 8bp barcode was fused to the forward 27F primer. A HotStarTaq Plus Master Mix Kit (Qiagen, Valencia, CA, United States) was used for PCR under the following conditions: $94^{\circ} \mathrm{C}$ for $5 \mathrm{~min}$, followed by 32 cycles of $94^{\circ} \mathrm{C}$ for $30 \mathrm{~s}, 55^{\circ} \mathrm{C}$ for $30 \mathrm{~s}$, and $72^{\circ} \mathrm{C}$ for $45 \mathrm{~s}$; and a final elongation step at $72^{\circ} \mathrm{C}$ for $5 \mathrm{~min}$. The PCR products was visualized and confirmed on a $1.8 \%$ agarose gel. All PCR amplicons from different samples were then purified using Agencourt AMPure beads (Agencourt Bioscience Corp., Beverly, MA, United States). The concentration of each purified PCR amplicon was determined using a Nanodrop ND-1000 spectrophotometer (NanoDrop Technologies Inc., Wilmington, Delaware, United States). Equimolar concentrations of the amplicons were then merged into a single tube and subjected to pyrosequencing at Molecular Research Laboratory (Shallowater, TX, United States) using 454 GS FLX titanium technology (454 Life Sciences, Branford, CT, United States). The amplicons were sequenced in the forward direction.

The 454 pyrosequencing data were analyzed using the Quantitative Insights Into Microbial Ecology (QIIME) Pipeline $^{1}$. Specifically, the low-quality sequence reads (reads lengths $<150 \mathrm{bp}$, ambiguous bases $>0$, homopolymers $>6$, barcode mismatches, and average quality scores $<25$ ) were discarded, and the 8-bp barcode was examined to distribute the sequences to proper samples. Then, chimeric sequence reads were identified and filtered using the Uchime algorithm based on a chimera-free reference database (Edgar et al., 2011) through the Usearch tool. The operational taxonomic units (OTUs) were generated at a $97 \%$ sequence-similarity level (Edgar,

${ }^{1}$ http://qiime.org/
2010). A representative sequence of each OTU was aligned with the PyNAST tool (Caporaso et al., 2010). The taxonomic identification of OTUs was obtained using the RDP Classifier with RDP as the reference database (Wang et al., 2007).

To standardize sampling efforts and to bring the pyrosequences of each sample onto a common scale, all samples were rarefied to an equal sequence depth (866 sequences per sample in this study). The relative abundance of all the phylotypes at each taxonomic level (phylum, class, order, family, and genus) was then summarized. Principal coordinate analysis (PCoA) was performed using the subsampled sequence data to determine the differences in the microbial community structures based on the weighted UniFrac distances, a method that accounts for the phylogenetic relationship between sequences and is thus more powerful than taxon-based measures (Lozupone and Knight, 2005; Hamady et al., 2010). Samples were clustered using UPGMA (unweighted pair group method with arithmetic mean) on weighted UniFrac distances. Three different complementary non-parametric analyses for multivariate data (Zhou et al., 2012), namely, the analysis of similarities (ANOSIM) (Clarke, 1993), non-parametric multivariate analysis of variance using distance matrices (adonis) (Anderson, 2001), and a multi-response permutation procedure (MRPP) (Mielke and Berry, 2001; McCune and Grace, 2002), were used to test for differences in the community structure between treatments. Weighted UniFrac distances were exploited for ANOSIM, Adonis, and MRPP analyses, and a Monte Carlo permutation was used to determine the statistical significance. ANOSIM, adonis, and MRPP were performed using the "vegan" package in the R environment.

For the relative abundance data of each of the taxa, the linear discriminant analysis (LDA) effect size (LEfSe) method $^{2}$ was used to test significant differences between treatments. Furthermore, Pearson correlation analysis was performed to understand the possible relationship between the bacterial taxa and the disease index. The Pearson correlation analysis were processed with the software SPSS.

\section{Accession Numbers}

The original sequence data have been deposited in the European Nucleotide Archive under accession number PRJEB19197.

\section{RESULTS}

\section{Dynamics of the Plant Disease Severity}

Based on the disease index, a parameter used to assess the disease severity, reported on days 7, 15, 25, and 35 after transplanting (Figure 1), PG-containing (i.e., $\mathrm{PG}$ and $\mathrm{PG}+\mathrm{IG}$ ) treatments significantly $(P<0.05)$ decreased the wilt index compared to the control during 35 days of cultivation (Figure 1). PG exhibited the most suppressive effect and completely suppressed the wilt throughout the 35-day period after transplanting. PG+IG treatment also significantly decreased the wilt index by $72.8 \%$ (Figure 1). However, the addition of CAME did not show an apparent suppressive effect. In addition, a significant negative

\footnotetext{
${ }^{2}$ http://huttenhower.sph.harvard.edu/galaxy/
} 


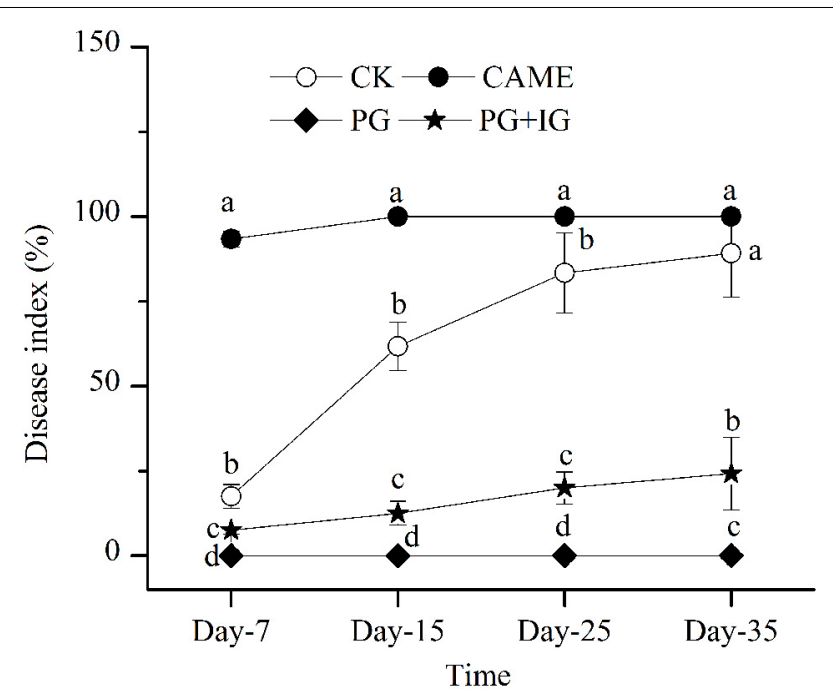

FIGURE 1 | Disease-index dynamics of Fusarium wilt on pepper during 35 days of cultivation. The designations CAME, PG, and PG+lG refer to the soils that were amended with different Brassicaceous seed meals (BSMs), namely, Camelina sativa, "Pacific Gold", or both "Pacific Gold" and "IdaGold," respectively. The designation CK refers to control (no BSM, fertilizer only). The disease severity of pepper was ranked into five levels: 1 , healthy; $2,1 / 4$ leaves turned yellow and fell off; 3, 1/3 leaves turned yellow and fell off; 4, 1/2 leaves turned yellow and fell off; 5 , dead. The disease index was then calculated according to the formula $\Sigma$ (the number of diseased plants $\times$ corresponding level $) \div$ the total number of investigated plants $\times 100$. The error bar represents the standard deviation of the mean. Different letters indicate significant differences at Duncan's significance level of 0.05 .

correlation $(r=-0.959, P=1.68 \mathrm{e}-4)$ was found between 2-propenyl glucosinolate content in BSMs and the disease index on day 35 . In other words, the suppressive efficacy was positively correlated with the 2-propenyl glucosinolate contained in the BSMs.

\section{Bacterial Diversity}

The 16S rRNA gene-based pyrosequencing technique was used to understand the bacterial community changes resulting from BSM amendment and to explore its relationship with plant disease severity. After applying all quality filters, a total of 53,564 highquality sequences across all samples or an average of 2,060 sequences per sample were obtained (Supplementary Table S1). All BSM treatments significantly decreased the bacterial richness and diversity before pepper planting based on the observation that the observed OTU number and phylogenetic diversity (PD) value were significantly $(P<0.05)$ lower under CAME, PG, and $\mathrm{PG}+\mathrm{IG}$ treatments in pre-planting soil samples (Figures $2 \mathrm{~A}, \mathbf{B}$ ). Although the significant decrease still existed after 35 days of pepper growth in PG and PG+IG treatments (Figures 2A,B), it was greatly weakened under all BSM treatments, as the difference between all BSM treatments and CK in terms of the observed OTU number and PD value in post-planting soil samples became smaller than that in pre-planting soil samples (Figures 2C,D).

Furthermore, after 35 days of pepper growth, in the treatments where the plant disease index was similar, the bacterial richness and diversity were also similar. Specifically, in the CK and CAME soil where the plant disease index was 89.2 and 100, respectively (Figure 1), there was no significant difference $(P>0.05)$ in terms of the observed OTU number and the PD value between these two treatments after 35 days of plant growth (Figures 2A,B), while in the PG and PG+IG treatments where the plant disease index was obviously decreased but was still similar (PG: 0; PG+IG: 24.2) (Figure 1), there was still no significant difference $(P>0.05)$ in terms of the observed OTUs number and the PD value (Figures 2A,B). Intriguingly, we also found that 35 days of pepper growth exerted no significant influence on the bacterial richness and diversity when BSM was not amended, while it had significant effect in BSM-amended soil (Figures 2A,B).

\section{Bacterial Community Structure}

The bacterial community structure is an overall reflection of the composition and abundance of different taxonomic population in a microbial community. Changes in bacterial community structure as affected by BSMs were thus assessed with the PCoA and UPGMA method based on the weighted UniFrac distances.

Twenty-five days of incubation with BSMs significantly changed the bacterial community structure. Specifically, samples from the BSM-amended treatments and unamended control were distributed in different regions of the PCoA space (Figure 3A) or grouped in different clusters in the UPGMA tree (Figure 3B). Three non-parametric multivariate statistical tests (ANOSIM, adonis, and MRPP) further indicated the significant influence $(P<0.05)$ of the BSMs on the bacterial community structure (Table 1). However, the influence of the BSMs on the bacterial community structure was weakened after 35 days of pepper growth based on the observation that the UniFrac distances, a measurement on the dissimilarity in the bacterial community structure, between BSM-amended treatments and CK in the postplanting soil samples were significantly $(P<0.05)$ smaller than in the pre-planting soil samples (Figure $3 \mathrm{C}$ ).

Furthermore, in the treatments where the plant disease index was similar, the dissimilarity in the bacterial community structure was smaller based on the observation that the UniFrac distances between CAME and CK (Figure 3C), where the plant disease index on day 35 was similar (Figure 1), was significantly $(P<0.05)$ smaller than that between PG and CK and between $\mathrm{PG}+\mathrm{IG}$ and $\mathrm{CK}$ (Figure 3C), where the plant disease index was distant (Figure 1) after 35 days of plant growth. Another interesting result was that 35 days of pepper growth had no significant influence on the bacterial community structure when no BSM was added but that it exerted a significant influence on the bacterial community structure in BSM-amended soil (Figures 3A,B and Table 1).

\section{Specific Bacterial Population Shifts at the High Taxonomic Level}

The changes in some specific bacterial populations resulting from BSM application may be related to differences in plant disease severity. To further understand the specific bacterial population that may be associated with the plant disease severity, the relative abundance of the phylotypes was summarized at 

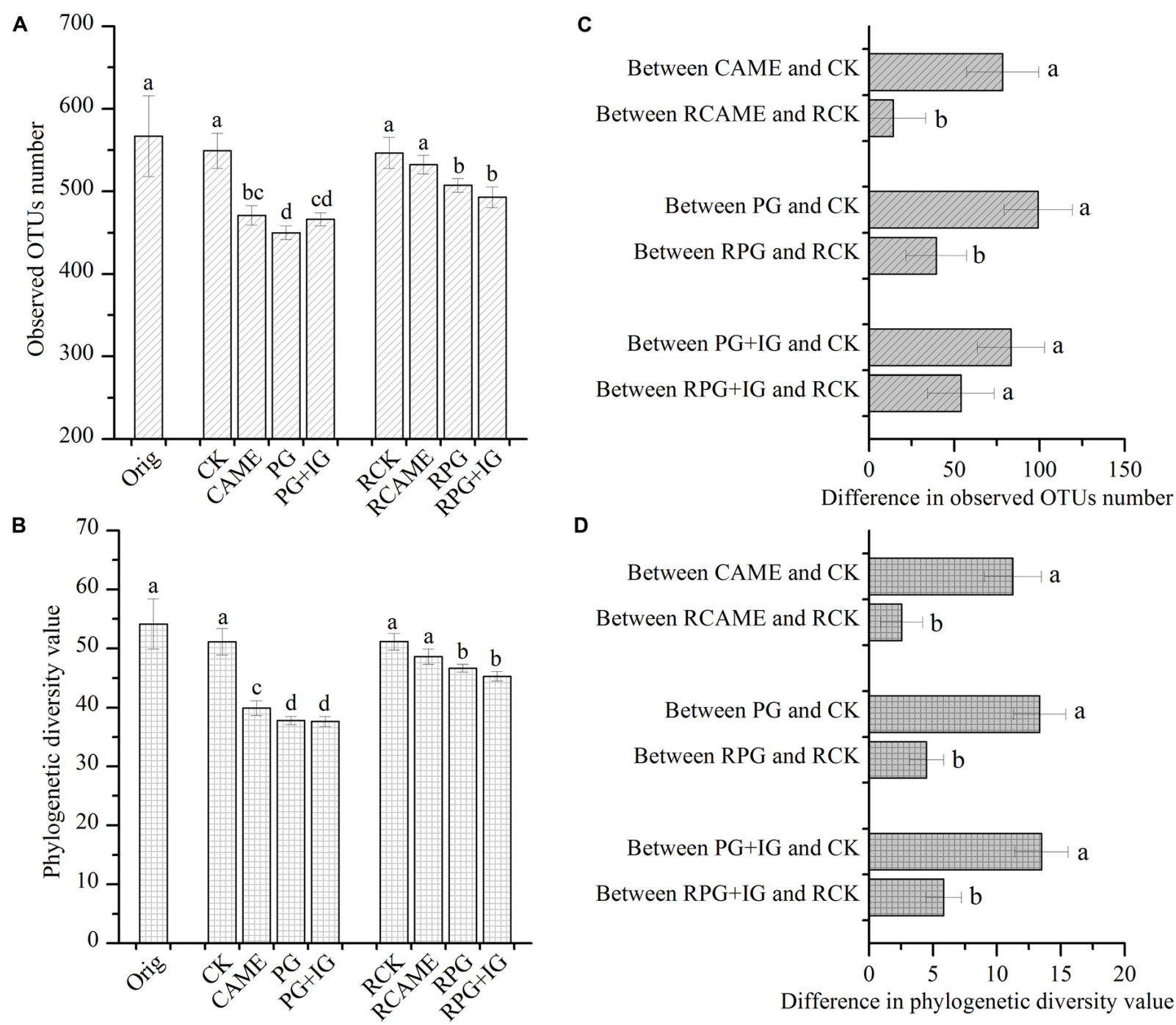

Difference in phylogenetic diversity value

FIGURE 2 | Observed operational taxonomic unit (OTU) number (A) and phylogenetic diversity value (B) under different treatments and the difference in the observed OTU number (C) and phylogenetic diversity value (D) between the BSM-amended and the control (CK) treatment. The OTU (at $97 \%$ similarity level) number and phylogenetic diversity value were calculated based on subsets of 866 reads per sample. The designation Orig represents the original soil that did not receive any treatment. The designations CAME, PG, and PG+IG represent the soils that were amended with different BSMs, namely, Camelina sativa, "Pacific Gold," or both "Pacific Gold" and "IdaGold", respectively. The designation CK represents the control (no seed meal, fertilizer only). The designations without the prefix "R" indicate that the samples were collected from the soils that were incubated for 25 days before pepper planting. The designations with the prefix "R" indicate that the soils were collected from the rhizosphere after 35 days of pepper growth. The error bar represents the standard deviation of the mean. Different letters indicate significant differences at Duncan's significance level of 0.05 .

the phylum or lower taxonomic level. Then, the correlation between the relative abundance of specific populations at the phylum or lower taxonomic level and observed disease index was analyzed.

The shift in the relative abundance of the main phyla/classes (those with relative abundance $>1 \%$ under at least one treatment were included) are shown in Figure 4. Of these main phyla/classes (a total of 15), 12 and 11 phylotypes were significantly changed in relative abundance by at least one BSM treatment in pre-planting soil and post-planting rhizosphere soil samples, respectively (Figure 5). Pearson correlation analysis revealed that the relative abundance of Actinobacteria and Gammaproteobacteria in pre-planting soil samples was negatively correlated $(P<0.05)$ with the day-35 disease index, with the correlation being strongest in Actinobacteria $(r=-0.953, P<0.05)$, while that of Chloroflexi and Gemmatimonadetes was positively correlated with the day-35 disease index, with the correlation being strongest in Chloroflexi $(r=0.760, P<0.05)$ (Table 2). The significant $(P<0.05)$ correlation between these four phylotypes and the day-35 disease index still existed after 35 days of pepper growth, indicating their possible function in manipulating plant disease (Table 2). As the bacterial biomass, indicated by the abundance of the 16S rRNA gene copies was not significantly influenced by BSM treatment 

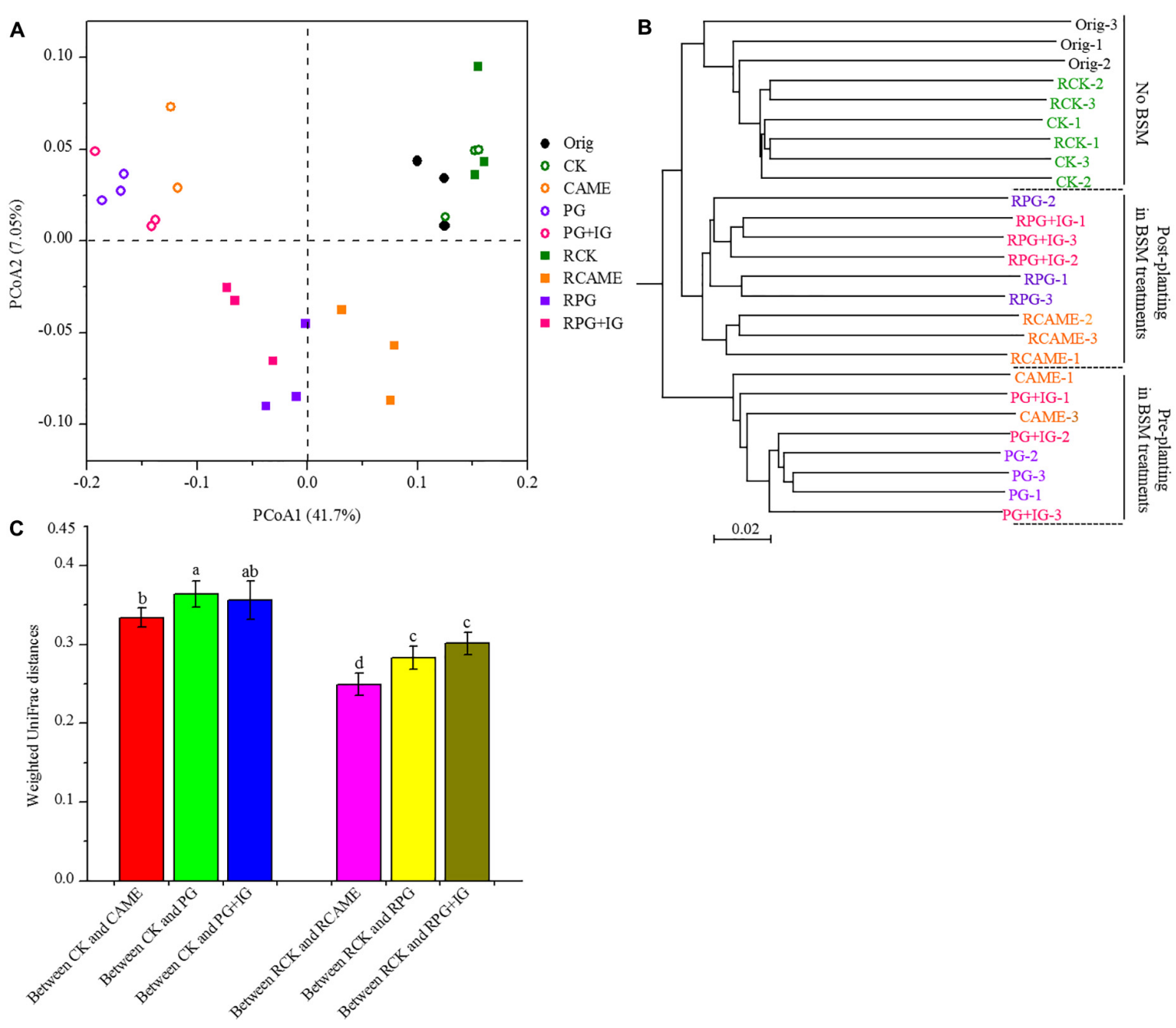

FIGURE 3 | Principal coordinate analysis (PCOA) (A) and unweighted pair group method with arithmetic mean (UPGMA) cluster analysis (B) of microbial communities and the weighted UniFrac distances of microbial communities between BSM-added and the control (CK) treatment (C). The PCoA plot and UPGMA cluster tree were obtained based on weighted UniFrac distances at a depth of 866 subsampled sequences per sample. In $\mathbf{A}$, percentages in parentheses denote the proportions of variation explained by each ordination axis. In B, three replicates for each treatment are indicated by the symbols "1," "2," and "3." In C, different letters represent significant differences by Duncan's multiple range test $(P<0.05)$. The error bars indicate the standard deviation of the means. A total of 27 samples were subjected to 454 pyrosequencing, but one sample (CAME-2) only generated 16 good quality sequences, which was exceptional lower than that observed in other samples. The sample CAME-2 was hence not included in the PCoA and UPGMA analyses or in the weighted UniFrac distances calculation. All other designations are the same as those in Figure 2.

(Supplementary Figure S1), changes in relative abundance could then reflect the absolute abundance of specific phylotypes.

\section{Specific Bacterial Population Shifts at a Lower Taxonomic Level}

The relative abundance of each phylotype was analyzed at the genus level to understand which bacterial populations were affected by BSM at a finer taxonomic level. Then, the correlation between the relative abundance of the main genera and the disease index was analyzed to explore the possible relationship between bacterial population shifts and plant disease.

Among the main genera (with relative abundance $>0.5 \%$ in at least one treatment), a total of 34 genera was significantly affected by at least one BSM treatment in both pre-planting and post-planting soil samples in terms of relative abundance (Figures 6A,B and Supplementary Figure S2). Of these significantly affected genera, the relative abundance of the following 4 genera from pre-planting soil samples, namely, two Streptomycetaceae-affiliated genera within Actinobacteria, i.e., Streptomyces and an unclassified genus; the genus Balneimonas within Alphaproteobacteria, and the genus Pseudoxanthomonas within Gammaproteobacteria, was significantly $(P<0.05)$ increased in the PG and PG+IG treatments (Figure 6A) where the plant disease was suppressed, but these genera (except for Pseudoxanthomonas) were not affected in CAME treatment (Figure 6A) where the day-35 plant disease index was similar to that observed in CK. Streptomyces and an unclassified genus 
within Actinobacteria were the strongest PG- or PG+IG-induced genera in both pre-planting and post-planting soil samples. Pearson correlation analysis further revealed a significantly negative correlation ( $\mathrm{r}$ ranged from -0.822 to $-0.864, P<0.05$ ) between the relative abundance of these 4 phylotypes in preplanting soil samples and the day- 35 plant disease index (Figure 6C). This significant correlation still existed after 35 days of pepper growth ( $\mathrm{r}$ ranged from -0.938 to -0.819 , $P<0.05)$. These 4 genera were hereinafter called significantly and negatively related phylotypes. In contrast, the relative abundance of the other 2 genera from pre-planting soil samples, namely, an unclassified genus within Acidobacteria and an unclassified genus

TABLE 1 | Significance tests using three statistical approaches to assess the effects of plant growth and BSMs on the overall microbial community structure.

\begin{tabular}{|c|c|c|c|c|c|c|}
\hline \multirow[t]{2}{*}{ Compared group } & \multicolumn{2}{|c|}{ adonis $^{\mathrm{a}}$} & \multicolumn{2}{|c|}{ ANOSIM $^{b}$} & \multicolumn{2}{|c|}{ MRPPc } \\
\hline & $\mathbf{F}$ & $P^{d}$ & $R$ & $P^{d}$ & $\delta$ & $P^{d}$ \\
\hline Orig vs. CK & 1.578 & 0.107 & 0.630 & 0.099 & 0.326 & 0.092 \\
\hline Orig vs. RCK & 2.790 & 0.086 & 0.685 & 0.106 & 0.316 & 0.106 \\
\hline \multicolumn{7}{|l|}{ Plant growth effect } \\
\hline CK vs. RCK & 1.243 & 0.107 & 0.615 & 0.107 & 0.291 & 0.119 \\
\hline CAME vs. RCAME & 5.858 & 0.029 & 0.889 & 0.036 & 0.292 & 0.034 \\
\hline PG vs. RPG & 10.678 & 0.032 & 0.793 & 0.034 & 0.251 & 0.032 \\
\hline$P G+\mid G$ vs. $R P G+I G$ & 3.115 & 0.037 & 0.721 & 0.035 & 0.268 & 0.030 \\
\hline \multicolumn{7}{|c|}{ BSM effect in pre-planting soil } \\
\hline CK vs. CAME & 10.822 & 0.036 & 0.952 & 0.034 & 0.298 & 0.042 \\
\hline CK vs. PG & 34.941 & 0.038 & 0.943 & 0.033 & 0.256 & 0.032 \\
\hline CK vs. $P G+I G$ & 21.736 & 0.036 & 0.921 & 0.031 & 0.287 & 0.029 \\
\hline CAME vs. PG & 3.336 & 0.099 & 0.502 & 0.087 & 0.243 & 0.101 \\
\hline CAME vs. $P G+I G$ & 1.460 & 0.081 & 0.523 & 0.092 & 0.276 & 0.126 \\
\hline$P G$ vs. $P G+\mid G$ & 1.921 & 0.104 & 0.519 & 0.084 & 0.239 & 0.103 \\
\hline \multicolumn{7}{|c|}{ BSM effect in post-planting soil } \\
\hline RCK vs. RCAME & 5.072 & 0.046 & 0.742 & 0.042 & 0.286 & 0.045 \\
\hline RCK vs. RPG & 8.748 & 0.040 & 0.815 & 0.040 & 0.288 & 0.042 \\
\hline RCK vs. RPG+IG & 16.682 & 0.038 & 0.895 & 0.038 & 0.272 & 0.034 \\
\hline RCAME vs. RPG & 2.286 & 0.048 & 0.712 & 0.045 & 0.290 & 0.046 \\
\hline RCAME vs. RPG+IG & 3.751 & 0.047 & 0.721 & 0.044 & 0.278 & 0.048 \\
\hline RPG vs. RPG+IG & 2.257 & 0.094 & 0.663 & 0.103 & 0.278 & 0.113 \\
\hline
\end{tabular}

All three significant tests are non-parametric multivariate analyses based on dissimilarities among samples. ${ }^{a}$ Permutational multivariate analysis of variance using distance matrices. The significance was obtained with F-tests based on sequential sums of squares from permutations of the raw data. ${ }^{b}$ Analysis of similarities. The $R$ was obtained based on the difference in the mean ranks between groups and within groups. The significance of observed $R$ was determined by permuting the grouping vector to obtain the empirical distribution of $R$ under the null model. ${ }^{C}$ Multi-response permutation procedure. The $\delta$ is the overall weighted mean of within-group means of the pairwise dissimilarities among sampling units. The significance test refers to as the fraction of permuted $\delta$ that is less than the observed $\delta .{ }^{d}$ A Bonferroni correction for the $P$ value was applied. Bold number indicates significance at a less than 0.05 level. The designation Orig represents the original soil that did not receive any treatment. The designations CAME, PG, and $P G+/ G$ represent the soils that were amended with different Brassicaceous seed meals (BSMs), namely, Camelina sativa, "Pacific Gold," or both "Pacific Gold," and "IdaGold," respectively. The designation CK represents the control (no seed meal, fertilizer only). The designations without the prefix " $R$ " indicate that the samples were collected from the soils that were incubated for 25 days before pepper planting. The designations with the prefix " $R$ " indicate that the soils were collected from the rhizosphere after 35 days of pepper growth. within Gemmatimonadetes, was significantly decreased in PGcontaining treatments (i.e., $\mathrm{PG}$ and $\mathrm{PG}+\mathrm{IG}$ ), but their relative abundance was not affected in the CAME treatment (Figure 6B). Pearson correlation analysis further indicated a significantly positive correlation $(r=0.847$ for the Acidobacteria-affiliated genus, $r=0.791$ for the Gemmatimonadetes-affiliated genus; $P<0.05)$ between the relative abundance of these 2 pre-planting phylotypes and the day-35 plant disease index (Figure 6C). The significant correlations still existed after 35 days of pepper growth ( $r=0.788$ for the Acidobacteria-affiliated genus, $r=0.702$ for the Gemmatimonadetes-affiliated genus; $P<0.05$ ). These 2 genera were hereinafter called significantly and positively related phylotypes. As no significant changes were found in terms of total bacterial biomass, as assessed by quantifying the $16 \mathrm{~S}$ rRNA gene using real-time quantitative PCR, under BSM treatments (Supplementary Figure S1), relative abundance data could then reflect the changes in the absolute abundance of specific taxa.

Streptomyces and an unclassified genus within Actinobacteria were the strongest PG- or PG+IG-induced genera in both pre-planting and post-planting soil samples. The unclassified genus within Actinobacteria exhibited approximately 15- and 14fold increases in relative abundance within 25 days of PG and PG+IG amendment, respectively, with its relative abundance increasing from $0.23 \%$ under $\mathrm{CK}$ to $3.62 \%$ and $3.41 \%$ under PG and PG+IG treatments, respectively (Figure 6A). This elevated relative abundance was maintained after 35 days of pepper growth, with its relative abundance increasing from $0.23 \%$ under CK to $3.54 \%$ under PG and $2.65 \%$ under PG+IG (Figure 6B). Similarly, the Actinobacteria-affiliated Streptomyces showed a significant increase (approximately a 2-4 times increase) in its relative abundance in PG and PG+IG in pre-planting and postplanting soil samples, with its relative abundance increasing from $0.65-0.80 \%$ under CK to $3.54-3.98 \%$ and $2.48-3.11 \%$ under PG and PG+IG treatments, respectively, in pre-planting and postplanting soil samples (Figures 6A,B). Correlation analysis further revealed that the relative abundance of these two phylotypes in both pre-planting and post-planting rhizosphere soil samples showed the strongest relationship with the day- 35 plant disease index (Figure 6C).

\section{DISCUSSION}

Plant-disease suppression by Brassicaceous biomass has long been attributed to glucosinolate-induced antimicrobial effects. Previous studies have shown that the inhibitory efficacy of isothiocyanate for plant diseases/plant pathogens varies depending on its structure and concentration (Aires et al., 2009; Taylor et al., 2014). It is therefore suspected that the content and composition of glucosinolate (the precursor of isothiocyanates) added within BSMs could influence the plant disease severity. Indeed, we found that it was the content of 2-propenyl (allyl) glucosinolate (within PG), or the capacity of the glucosinolate to produce 2-propenyl (allyl) glucosinolate, rather than 10-methylsulfinyl-decyl-glucosinolate (within CAME), that was negatively associated with disease severity. For instance, in the PG and PG+IG treatments with 2-propenyl (allyl) glucosinolate, the 


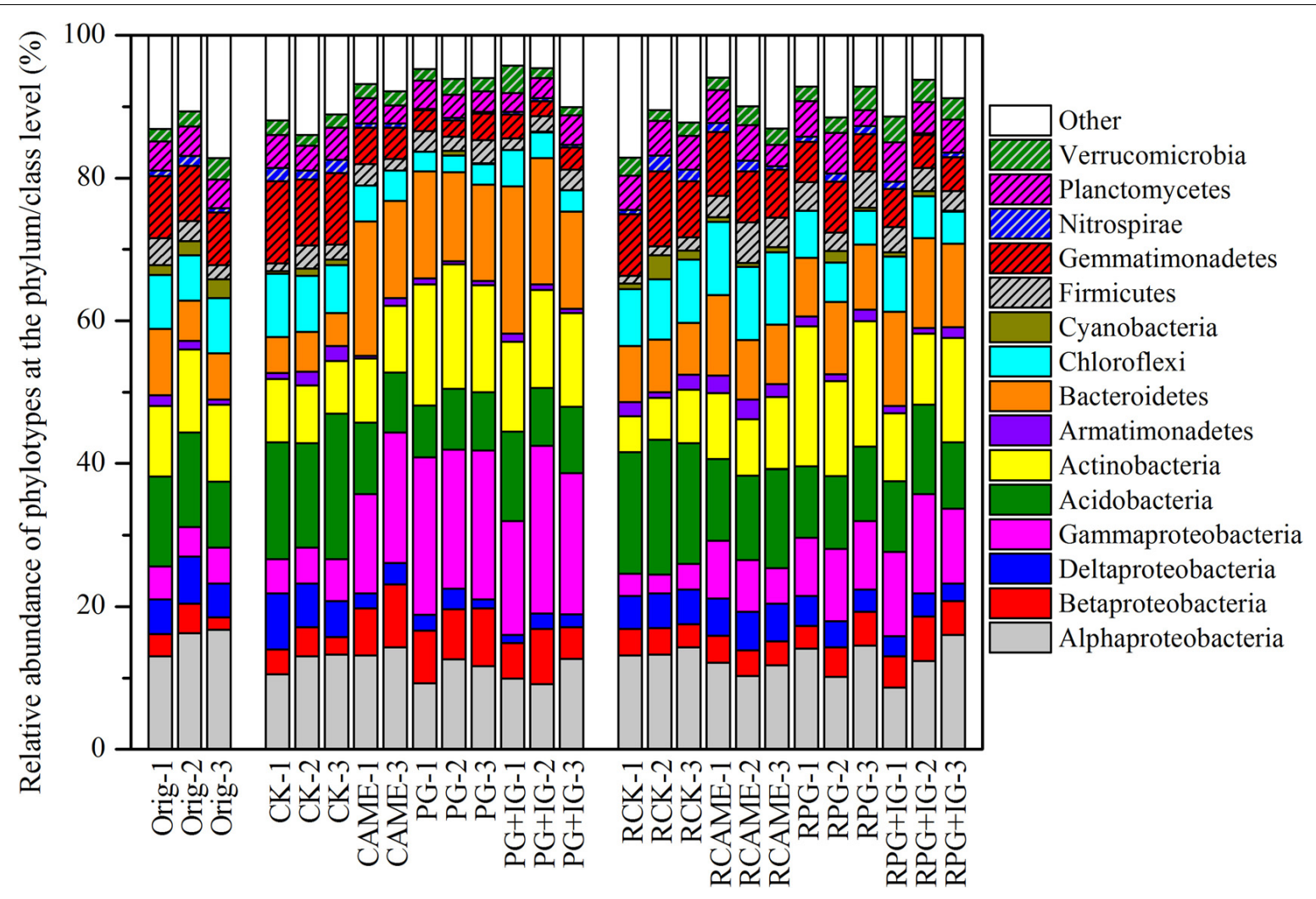

FIGURE 4 | Relative abundance of the phylotypes at the phylum or class (only for Proteobacteria) level. The phylotypes which could be classified at the phylum or class (only for Proteobacteria) level and had relative abundance $>1 \%$ in at least on treatment are presented. All other designations are the same as those in

Figures 2, 3.

wilt disease was significantly suppressed, while in the CAME treatment with no 2-propenyl (allyl) glucosinolate, the disease index developed immediately to a high level. The phenomenon may be attributed to the proliferation or suppression of the Fusarium wilt pathogen resulting from treatment with the different BSMs. Our previous work (Ma et al., 2015), which focused on fungal communities after BSM incorporation based on a different run of the experiment (although the design follows that in this study), found that the growth of Fusarium was suppressed in PG-containing treatments, while it was promoted under a CAME treatment, and this finding supported our speculation.

In addition to the antimicrobial effects of 2-propenyl (allyl) glucosinolate within applied BSMs leading to the difference in plant disease severity, the changes in bacterial communities resulting from BSM incorporation may be one of the microbial mechanisms contributing to variation in plant disease severity. At a course taxonomic level, Chloroflexi, the phylum that showed the strongest positive correlation with the disease index in our study has been regarded as disease-inducible bacteria (Niu et al., 2016) and has been found to be positively correlated with the morbidity of tobacco bacterial wilt (Niu et al., 2016) and cucumber Fusarium wilt (Li et al., 2016). Actinobacteria, which has been identified as the most dynamic phylum in a soil suppressive to the fungal root pathogen
Rhizoctonia solani (Cordovez et al., 2015), was also found to have the strongest negative correlation with the disease index in our study. Similar to our finding, higher relative abundance of Actinobacteria was also found in a rhizosphere soil where the incidence of watermelon Fusarium wilt was decreased (Xu et al., 2015). We suspect that the proliferation of beneficial bacterial populations such as Actinobacteria and the suppression of unfavorable phylotypes for plant disease, such as Chloroflexi was one of the important microbial mechanisms contributing to the wilt suppression in PGcontaining treatments.

Furthermore, a close relationship between bacterial population shifts and plant disease severity was found at a finer taxonomic level. The Actinobacteria-affiliated unclassified genus and Streptomyces were the strongest PG- and PG+IGinduced genera, with their relative abundance increased by 14-15-fold for the unclassified genus and by 3.8-4.4-fold for Streptomyces after 25 days of incubation. This increase in relative abundance was maintained after an additional 35 days of pepper growth. These two phylotypes also showed the strongest negative correlation with the plant disease index. Actinobacteria, and specifically Streptomycetaceae, have been found to contain a number of strains contributing to disease-suppressive soils and antifungal activities (Viaene et al., 2016). Streptomyces, the largest genus in Actinobacteria (Viaene et al., 2016), has been shown 

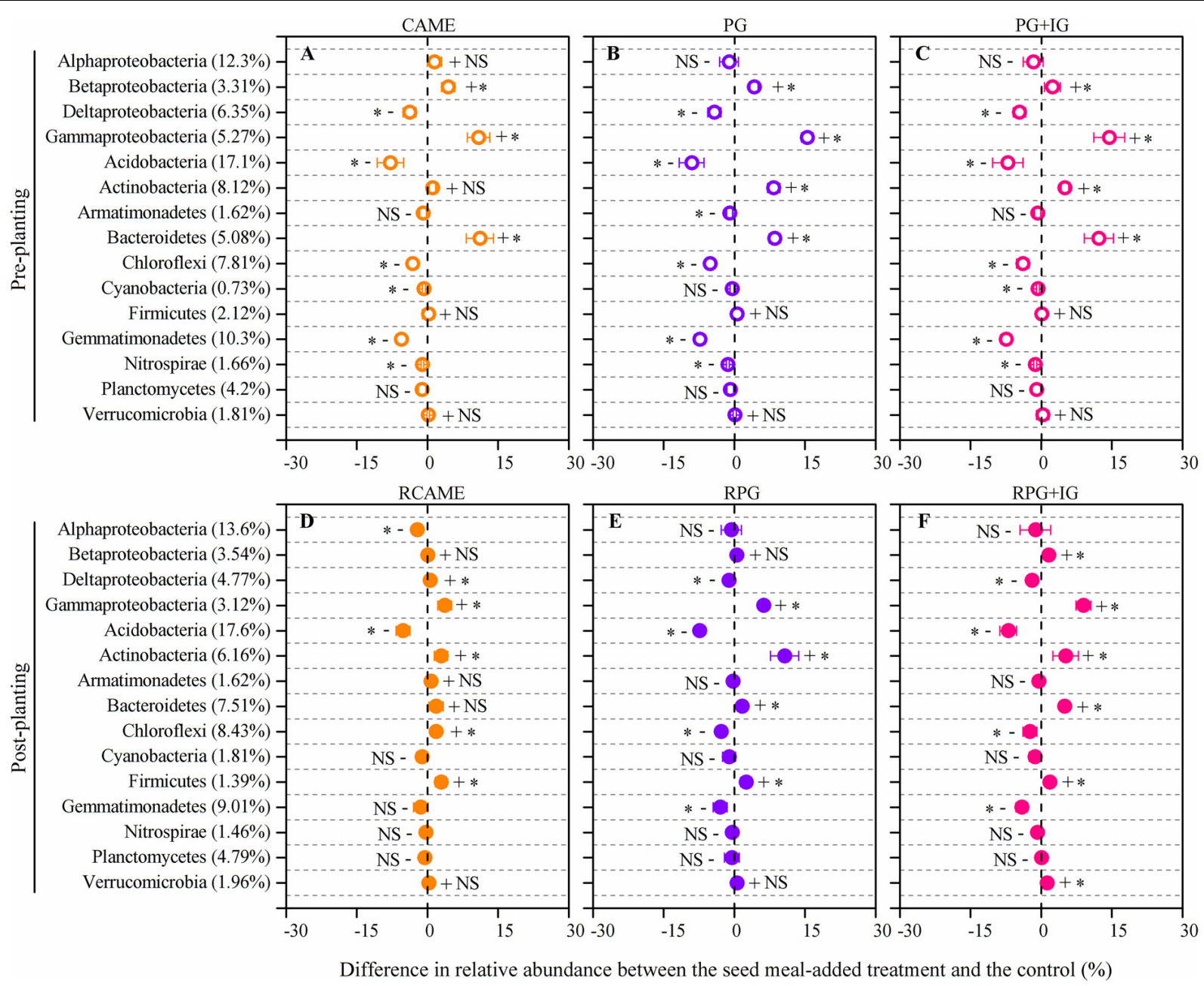

Difference in relative abundance between the seed meal-added treatment and the control (\%)

FIGURE 5 | Differences in relative abundance between the BSM-added treatment and the control for those phylotypes presented in Figure 4 . The net difference in relative abundance was calculated as the relative abundance under BSM-amended treatment - the relative abundance of the phylotypes under control treatment. The LEFSe method was used for testing whether there is a statistically significant difference between the BSM treatments and the control. The LEFSe result is shown in Supplementary Table S2. The error bar denotes the standard deviation of the mean. The percentage in parentheses denotes the relative abundance in the control treatment. The symbols "+" and "-" indicate that the relative abundance was increased or decreased compared with the control. The symbol "*" denotes significant differences at $P<0.05$; NS denotes no significant difference $(P>0.05)$. All other designations are the same as those in Figure 2.

to suppress a range of plant pathogens (Castillo et al., 2002; Cohen et al., 2005) through producing antibiotics (Lucas et al., 2013) and other bioactive metabolites, including volatile organic compounds (Cordovez et al., 2015) and cell wall-degrading enzymes, such as chitinases (Hoster et al., 2005). The ability of Streptomyces strains to suppress plant diseases, such as Rhizoctonia solani damping-off on tomato and Fusarium wilt on chickpea caused by Fusarium oxysporum, has been confirmed through greenhouse and field studies (Gopalakrishnan et al., 2011; Goudjal et al., 2014). Therefore, the disease suppression by PG-containing treatments in our study may be explained by the significant increase in Actinobacteria-affiliated genera by $P G$ and $P G+I G$ treatments, which also contributed to the inhibition of the growth of the Fusarium wilt pathogen and hence the decrease in the severity of Fusarium wilt on pepper. Indeed, the suppression of Fusarium was found in
PG-containing treatments where the wilt disease was suppressed greatly in our previous study based on another experimental run (Ma et al., 2015). For the positively correlated genera, i.e., the RB40-affiliated genus within Acidobacteria and an unclassified genus within Gemmatimonadetes, because both of them cannot be classified at the genus level, it is difficult to relate their biological properties to plant disease. It is likely that these two genera formed cooperative relationships with the plant pathogen, leading to severe plant disease, although the mechanisms behind this process remain to be clarified. To some extent, this speculation was supported by an in silico approach-based study (da Silva et al., 2014), which found that the non-pathogenic bacterial species (e.g., Erwinia toletana) and the pathogen (Pseudomonas savastanoi pv. savastanoi) formed a cooperative interaction via quorum-sensing signal-sharing, and the outcome of this interaction was a more aggressive knot 


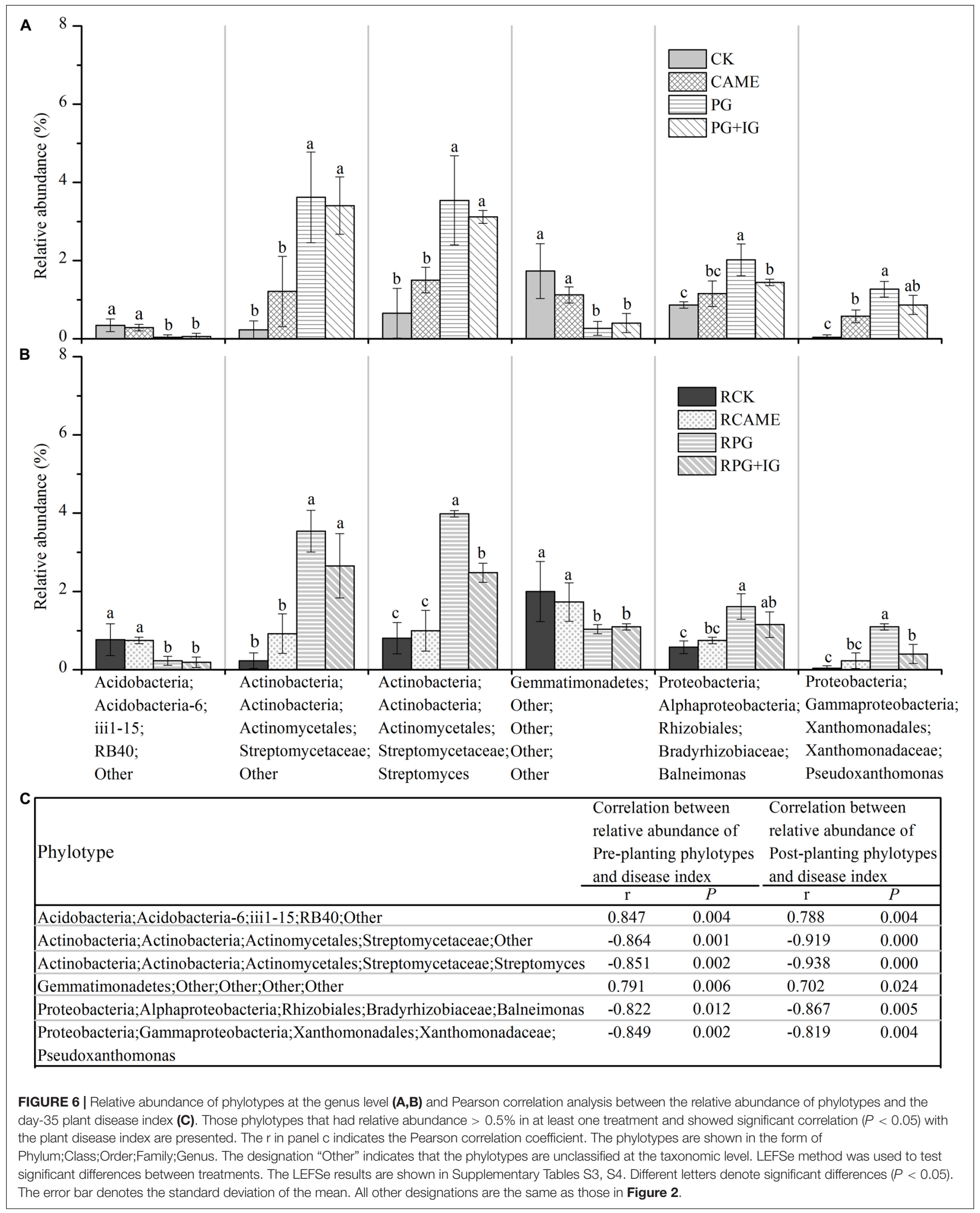


disease on olive when co-inoculations were made compared with single inoculations.

BSM addition decreased the bacterial richness and diversity before pepper planting and altered the bacterial community structure in both pre-planting soil and post-planting rhizosphere soil. The decrease in the bacterial richness and diversity was similar to the observations in a soil microcosm-based study (Hollister et al., 2013), which found that the addition of glucosinolate-containing BSM resulted in $38.8 \%$ and $22.0 \%$ decreases in the OTU number and Shannon index of the bacterial community, respectively, after 28 days of incubation. Another field trial-based study (Wei et al., 2016) also demonstrated a decrease in the OTU number and Shannon index in soil treated with Brassica seed meal. Similar to our finding, significant changes in the bacterial community structure resulting from BSM incorporation was also found in previous studies (Hollister et al., 2013). The changes in the bacterial community structure may be due to the fact that glucosinolates and their breakdown products could act as a factor of selection on soil microbial communities. To some extent, this speculation was supported by a previous study (Bressan et al., 2009) showing that glucosinolate and its hydrolysis product could have important repercussions for soil microbial communities in the rhizosphere and that even minor modification in the profile of glucosinolate produced by the root of Arabidopsis thaliana significantly influenced the microbes in the rhizosphere and plant roots.

Intriguingly, we showed that the original soil was more easily affected by the BSMs than by 35 days of pepper growth based on the phenomenon that 35 days of pepper growth exerted no significant influence on the bacterial richness, diversity, and structure when BSM was not amended, while it showed a significant effect on BSM-amended soil. Once the bacterial community in the original soil was disturbed by the BSMs, the 35 days of pepper growth tended to help the bacterial communities to recover from the disturbed state to be more similar to the original state. In other words, the effect of BSMs on the bacterial community was weakened by 35 days of pepper growth. However, in our previous study (which reported a different run of the experiment, although the design follows that in this study) (Ma et al., 2015), unlike bacterial communities, BSM application altered the fungal community structure, but the fungal community did not show any indication of resilience (i.e., returned to their nonamended control state) after pepper growth. In other words, the effect of 35 days of pepper growth on the fungal community was minor. This observation may be because of fungi being more sensitive to BSMs than bacteria. A previous study has shown that the greatest effects of BSM addition occurred within the fungal portion of soil communities, although both bacterial and fungal communities were affected by BSM amendment (Hollister et al., 2013), and this finding supported our speculation. Similar to our finding, Hollister et al. (2013) revealed that Brassica juncea seed meal treatment altered soil fungal communities dramatically and that its influence could be sustained for a longer time than those imparted upon the bacterial community.

Furthermore, the finding that once disturbed by BSMs, the bacterial community tended to shift back toward the prior state after 35 days of pepper growth may be explained by the fact that the soil sample used in this study was collected from a commercial chili pepper field where Fusarium wilt was a consistent and serious problem due to consistent planting, so that the bacteria

TABLE 2 | Pearson correlation analysis between the relative abundance of phylotypes at the phylum or class (only for Proteobacteria) level and the day-35 plant disease index.

\begin{tabular}{lccc}
\hline Phylotype & \multicolumn{1}{c}{$\begin{array}{c}\text { Correlation between the relative abundance of } \\
\text { pre-planting phylotype and day-35 disease index }\end{array}$} & \multicolumn{2}{c}{$\begin{array}{c}\text { Correlation between the relative abundance of } \\
\text { post-planting phylotype and day-35 disease index }\end{array}$} \\
\cline { 2 - 4 } & $\boldsymbol{r}$ & 0.073 & $\boldsymbol{r}$ \\
\hline Alphaproteobacteria & 0.560 & 0.250 & -0.092 \\
Betaproteobacteria & -0.379 & 0.054 & -0.507 \\
Deltaproteobacteria & 0.614 & 0.010 & $0.828^{*}$ \\
Gammaproteobacteria & $-0.736^{*}$ & 0.062 & $-0.694^{*}$ \\
Acidobacteria & 0.580 & $2.073 e-5$ & $0.677^{*}$ \\
Actinobacteria & $-0.953^{*}$ & 0.173 & $-0.797^{*}$ \\
Armatimonadetes & 0.443 & 0.186 & 0.625 \\
Bacteroidetes & -0.431 & 0.007 & -0.439 \\
Chloroflexi & $0.760^{*}$ & 0.421 & $0.871^{*}$ \\
Cyanobacteria & 0.270 & 0.503 & 0.314 \\
Firmicutes & -0.227 & 0.012 & -0.224 \\
Gemmatimonadetes & $0.723^{*}$ & 0.017 & 0.018 \\
Nitrospirae & $0.699^{*}$ & 0.441 & 0.016 \\
Planctomycetes & 0.259 & 0.857 & 0.002 \\
Verrucomicrobia & -0.062 & 0.336 & 0.001 \\
\hline
\end{tabular}

The phylotypes shown in Figure 4 are included here for correlation analyses. The $r$ indicates the correlation coefficient. The $r$ that is statistically significant $(P<0.05)$ is indicated by the symbol "*". 
formed a relatively stable structure to make themselves adaptable to continuous cropping; however, BSMs had never been used in that field. These observations may explain why the bacterial community structure in the original soil was more easily affected by the sudden BSM incorporation than by the usual and "already accustomed to" practice, namely, planting. Similarly, this may also explain why in the case when the bacterial community was changed in terms of the bacterial richness, diversity, and structure, it tended to recover to its original state after pepper planting. The paramount role of further pepper planting in recovering the bacterial communities in this study explained one of the reasons why continuous cropping usually makes the soil unfavorable for plant growth.

In summary, the suppression of Fusarium wilt on pepper was achieved by application of PG-containing BSMs. In addition to wilt suppression, the PG-containing BSM addition also altered the bacterial community structure and decreased the bacterial richness and diversity. Pepper planting could weaken the BSM effect on the bacteria communities. Besides through chemical/biocidal action of 2-propenyl (allyl) glucosinolate within applied BSMs that suppressed Fusarium wilt on pepper, the changes in bacterial populations at the phylum/class and genus levels resulting from PG-containing BSM treatments, such as the significant increase in Actinobacteria-affiliated genera, very common disease-suppressive phylotypes, and the significant decrease in Chloroflexi, a reported diseaseinducible population (Niu et al., 2016), are suspected to be one of the microbial mechanisms that are involved in PG-containing BSM-induced disease suppression. Further studies should focus on evaluating the contribution of specific taxa (such as Actinobacteria-affiliated genera) to disease suppression in situ and testifying the viability and effectiveness of the method of manipulation of the resident bacterial taxa (e.g., Actinobacteria-affiliated genera) for plant disease control.

\section{REFERENCES}

Aires, A., Mota, V. R., Saavedra, M. J., Monteiro, A. A., Simões, M., Rosa, E. A. S., et al. (2009). Initial in vitro evaluations of the antibacterial activities of glucosinolate enzymatic hydrolysis products against plant pathogenic bacteria. J. Appl. Microbiol. 106, 2096-2105. doi: 10.1111/j.1365-2672.2009.04181.x

Anderson, M. J. (2001). A new method for non-parametric multivariate analysis of variance. Austral Ecol. 26, 32-46. doi: 10.1111/j.1442-9993.2001.01070.pp.x

Borek, V., and Morra, M. J. (2005). Ionic thiocyanate (SCN-) production from 4hydroxybenzyl glucosinolate contained in Sinapis alba seed meal. J. Agric. Food Chem. 53, 8650-8654. doi: 10.1021/jf051570r

Bressan, M., Roncato, M.-A., Bellvert, F., Comte, G., Haichar, F. E. Z., Achouak, W., et al. (2009). Exogenous glucosinolate produced by Arabidopsis thaliana has an impact on microbes in the rhizosphere and plant roots. ISME J. 3, 1243-1257. doi: 10.1038 /ismej.2009.68

Brown, P. D., and Morra, M. J. (1997). "Control of soil-borne plant pests using glucosinolate-containing plants," in Advances in Agronomy, ed. D. L. Sparks (Cambridge, MA: Academic Press), 167-231.

Caporaso, J. G., Bittinger, K., Bushman, F. D., Desantis, T. Z., Andersen, G. L., and Knight, R. (2010). PyNAST: a flexible tool for aligning sequences to a template alignment. Bioinformatics 26, 266-267. doi: 10.1093/bioinformatics/btp636

Castillo, U. F., Strobel, G. A., Ford, E. J., Hess, W. M., Porter, H., Jensen, J. B., et al. (2002). Munumbicins, wide-spectrum antibiotics produced by Streptomyces

\section{AUTHOR CONTRIBUTIONS}

GR contributed to conception, data analysis, and interpretation and drafted and critically revised the manuscript. YM contributed to conception, design, data acquisition, and interpretation and critically revised the manuscript. DG, TG, $\mathrm{PH}, \mathrm{EP}$, and MG contributed to conception and critically revised the manuscript.

\section{FUNDING}

This work was supported by the Ministry of Science and Technology 973 project (No. 2015CB150500), National Science Foundation for Young Scientists of China (No. 41601266), Special Fund of China Postdoctoral Science Foundation (No. 2017T100340), China Postdoctoral Science Foundation (No. 2016M600387), and Jiangsu Postdoctoral Science Foundation, China (No. 1601061B).

\section{ACKNOWLEDGMENTS}

We thank Prof. Xiangzhen Li and Dr. Jiabao Li from Chengdu Institute of Biology, Chinese Academy of Sciences, Dr. Ruibo Sun from Institute of Genetic and Developmental Biology, Chinese Academy of Sciences, and Yuntao Li from Institute of Soil Science, Chinese Academy of Sciences, for their help in the statistical analysis. We thank the reviewers for the great suggestions, which helped to improve the paper greatly.

\section{SUPPLEMENTARY MATERIAL}

The Supplementary Material for this article can be found online at: https://www.frontiersin.org/articles/10.3389/fmicb. 2018.00185/full\#supplementary-material

NRRL 30562, endophytic on Kennedia nigriscans. Microbiology 148, 2675-2685. doi: 10.1099/00221287-148-9-2675

Clarke, K. R. (1993). Nonparametric multivariate analyses of changes in community structure. Aust. J. Ecol. 18, 117-143. doi: 10.1111/j.1442-9993.1993. tb00438.x

Cohen, M. F., Yamasaki, H., and Mazzola, M. (2005). Brassica napus seed meal soil amendment modifies microbial community structure, nitric oxide production and incidence of Rhizoctonia root rot. Soil Biol. Biochem. 37, 1215-1227. doi: 10.1016/j.soilbio.2004.11.027

Cordovez, V., Carrion, V. J., Etalo, D. W., Mumm, R., Zhu, H., Van Wezel, G. P., et al. (2015). Diversity and functions of volatile organic compounds produced by Streptomyces from a disease-suppressive soil. Front. Microbiol. 6:1081. doi: 10.5589/fmicb.2015.01081

da Silva, D. P., Castañeda-Ojeda, M. P., Moretti, C., Buonaurio, R., Ramos, C., and Venturi, V. (2014). Bacterial multispecies studies and microbiome analysis of a plant disease. Microbiology 160, 556-566. doi: 10.1099/mic.0. 074468-0

Edgar, R. C. (2010). Search and clustering orders of magnitude faster than BLAST. Bioinformatics 26, 2460-2461. doi: 10.1093/bioinformatics/ btq461

Edgar, R. C., Haas, B. J., Clemente, J. C., Quince, C., and Knight, R. (2011). UCHIME improves sensitivity and speed of chimera detection. Bioinformatics 27, 2194-2200. doi: 10.1093/bioinformatics/btr381 
Fierer, N., Jackson, J. A., Vilgalys, R., and Jackson, R. B. (2005). Assessment of soil microbial community structure by use of taxon-specific quantitative PCR assays. Appl. Environ. Microbiol. 71, 4117-4120. doi: 10.1128/AEM.71.7.41174120.2005

Gopalakrishnan, S., Pande, S., Sharma, M., Humayun, P., Kiran, B. K., Sandeep, D., et al. (2011). Evaluation of actinomycete isolates obtained from herbal vermicompost for the biological control of Fusarium wilt of chickpea. Crop Prot. 30, 1070-1078. doi: 10.1016/j.cropro.2011.03.006

Goudjal, Y., Toumatia, O., Yekkour, A., Sabaou, N., Mathieu, F., and Zitouni, A. (2014). Biocontrol of Rhizoctonia solani damping-off and promotion of tomato plant growth by endophytic actinomycetes isolated from native plants of Algerian Sahara. Microbiol. Res. 169, 59-65. doi: 10.1016/j.micres.2013. 06.014

Hamady, M., Lozupone, C., and Knight, R. (2010). Fast UniFrac: facilitating highthroughput phylogenetic analyses of microbial communities including analysis of pyrosequencing and PhyloChip data. ISME J. 4, 17-27. doi: 10.1038/ismej. 2009.97

Hoagland, L., Carpenter-Boggs, L., Reganold, J. P., and Mazzola, M. (2008). Role of native soil biology in Brassicaceous seed meal-induced weed suppression. Soil Biol. Biochem. 40, 1689-1697. doi: 10.1016/j.soilbio.2008. 02.003

Hollister, E. B., Engledow, A. S., Hammett, A. J. M., Provin, T. L., Wilkinson, H. H., and Gentry, T. J. (2010). Shifts in microbial community structure along an ecological gradient of hypersaline soils and sediments. ISME J. 4, 829-838. doi: 10.1038/ismej.2010.3

Hollister, E. B., Hu, P., Wang, A. S., Hons, F. M., and Gentry, T. J. (2013). Differential impacts of brassicaceous and nonbrassicaceous oilseed meals on soil bacterial and fungal communities. FEMS Microbiol. Ecol. 83, 632-641. doi: 10.1111/1574-6941.12020

Hoster, F., Schmitz, J. E., and Daniel, R. (2005). Enrichment of chitinolytic microorganisms: isolation and characterization of a chitinase exhibiting antifungal activity against phytopathogenic fungi from a novel Streptomyces strain. Appl. Microbiol. Biotechnol. 66, 434-442. doi: 10.1007/s00253-0041664-9

Hu, P., Hollister, E. B., Somenahally, A. C., Hons, F. M., and Gentry, T. J. (2015). Soil bacterial and fungal communities respond differently to various isothiocyanates added for biofumigation. Front. Microbiol. 5:729. doi: 10.3389/ fmicb.2014.00729

Hu, P., Wang, A. S., Engledow, A. S., Hollister, E. B., Rothlisberger, K. L., Matocha, J. E., et al. (2011). Inhibition of the germination and growth of Phymatotrichopsis omnivora (cotton root rot) by oilseed meals and isothiocyanates. Appl. Soil Ecol. 49, 68-75. doi: 10.1016/j.apsoil.2011. 06.014

Huse, S. M., Dethlefsen, L., Huber, J. A., Welch, D. M., Relman, D. A., and Sogin, M. L. (2008). Exploring microbial diversity and taxonomy using SSU rRNA hypervariable tag sequencing. PLOS Genet. 4:e1000255. doi: 10.1371/journal. pgen.1000255

Ibekwe, A. M., Papiernik, S. K., Gan, J., Yates, S. R., Yang, C. H., and Crowley, D. E. (2001). Impact of fumigants on soil microbial communities. Appl. Environ. Microbiol. 67, 3245-3257. doi: 10.1128/aem.67.7.3245-3257. 2001

Kobayashi, K. (2004). Factors affecting phytotoxic activity of allelochemicals in soil. Weed Biol. Manag. 4, 1-7. doi: 10.1111/j.1445-6664.2003.00112.x

LaMondia, J. A. (2015). Fusarium wilt of tobacco. Crop Prot. 73, 73-77. doi: 10.1016/j.cropro.2015.03.003

Larkin, R. P., and Griffin, T. S. (2007). Control of soilborne potato diseases using Brassica green manures. Crop Prot. 26, 1067-1077. doi: 10.1016/j.cropro.2006. 10.004

Lazzeri, L., Baruzzi, G., Malaguti, L., and Antoniacci, L. (2003). Replacing methyl bromide in annual strawberry production with glucosinolate-containing green manure crops. Pest Manag. Sci. 59, 983-990. doi: 10.1002/ps.726

Lemanceau, P., and Alabouvette, C. (1993). Suppression of fusarium wilts by fluorescent pseudomonads: mechanisms and applications. Biocontrol Sci. Technol. 3, 219-234. doi: 10.1080/09583159309355278

Li, R., Shen, Z. Z., Sun, L., Zhang, R. F., Fu, L., Deng, X. H., et al. (2016). Novel soil fumigation method for suppressing cucumber Fusarium wilt disease associated with soil microflora alterations. Appl. Soil Ecol. 101, 28-36. doi: 10.1016/j.apsoil. 2016.01.004
Lozupone, C., and Knight, R. (2005). UniFrac: a new phylogenetic method for comparing microbial communities. Appl. Environ. Microbiol. 71, 8228-8235. doi: 10.1128/aem.71.12.8228-8235.2005

Lucas, X., Senger, C., Erxleben, A., Grüning, B. A., Döring, K., Mosch, J., et al. (2013). StreptomeDB: a resource for natural compounds isolated from Streptomyces species. Nucleic Acids Res. 41, D1130-D1136. doi: 10.1093/nar/ gks1253

Ma, Y., Gentry, T., Hu, P., Pierson, E., Gu, M. M., and Yin, S. (2015). Impact of brassicaceous seed meals on the composition of the soil fungal community and the incidence of Fusarium wilt on chili pepper. Appl. Soil Ecol. 90, 41-48. doi: 10.1016/j.apsoil.2015.01.016

Mazzola, M., and Brown, J. (2010). Efficacy of brassicaceous seed meal formulations for the control of apple replant disease in conventional and organic production systems. Plant Dis. 94, 835-842. doi: 10.1094/pdis-94-70835

Mazzola, M., and Mullinix, K. (2005). Comparative field efficacy of management strategies containing Brassica napus seed meal or green manure for the control of apple replant disease. Plant Dis. 89, 1207-1213. doi: 10.1094/pd-891207

McCune, B., and Grace, J. B. (2002). Analysis of Ecological Communities. Gleneden Beach, OR: MjM Software Design, 300.

Mielke, P. W., and Berry, K. J. (2001). "Permutation methods: a distance function approach," in Springer Series in Statistics, eds P. Bickel, P. Diggle, U. Gather, and S. Zeger (Berlin: Springer). doi: 10.1007/978-1-4757-3449-2

Miyatake, K., Saito, T., Negoro, S., Yamaguchi, H., Nunome, T., Ohyama, A. et al. (2016). Detailed mapping of a resistance locus against Fusarium wilt in cultivated eggplant (Solanum melongena). Theor. Appl. Genet. 129, 357-367. doi: 10.1007/s00122-015-2632-8

Morra, M. J., and Kirkegaard, J. A. (2002). Isothiocyanate release from soilincorporated Brassica tissues. Soil Biol. Biochem. 34, 1683-1690. doi: 10.1016/ S0038-0717(02)00153-0

Mowlick, S., Yasukawa, H., Inoue, T., Takehara, T., Kaku, N., Ueki, K., et al. (2013). Suppression of spinach wilt disease by biological soil disinfestation incorporated with Brassica juncea plants in association with changes in soil bacterial communities. Crop Prot. 54, 185-193. doi: 10.1016/j.cropro.2013. 08.012

Niu, J. J., Rang, Z. W., Zhang, C., Chen, W., Tian, F., Yin, H. Q., et al. (2016). The succession pattern of soil microbial communities and its relationship with tobacco bacterial wilt. BMC Microbiol. 16:233. doi: 10.1186/s12866-0160845-x

Omirou, M., Rousidou, C., Bekris, F., Papadopoulou, K. K., MenkissoglouSpiroudi, U., Ehaliotis, C., et al. (2011). The impact of biofumigation and chemical fumigation methods on the structure and function of the soil microbial community. Microb. Ecol. 61, 201-213. doi: 10.1007/s00248-0109740-4

Rumberger, A., and Marschner, P. (2003). 2-Phenylethylisothiocyanate concentration and microbial community composition in the rhizosphere of canola. Soil Biol. Biochem. 35, 445-452. doi: 10.1016/s0038-0717(02)0 0296-1

Scott, J. S., and Knudsen, G. R. (1999). Soil amendment effects of rape (Brassica napus) residues on pea rhizosphere bacteria. Soil Biol. Biochem. 31, 1435-1441. doi: 10.1016/s0038-0717(99)00064-4

Shi, L., Du, N. S., Yuan, Y. H., Shu, S., Sun, J., and Guo, S. R. (2016). Vinegar residue compost as a growth substrate enhances cucumber resistance against the Fusarium wilt pathogen Fusarium oxysporum by regulating physiological and biochemical responses. Environ. Sci. Pollut. Res. 23, 18277-18287. doi: 10.1007/s11356-016-6798-7

Smolinska, U., Knudsen, G. R., and Morra, M. J. (1997). Inhibition of Aphanomyces euteiches f. sp. pisi by volatiles produced by hydrolysis of Brassica napus seed meal. Plant Dis. 81, 288-292. doi: 10.1094/PDIS.1997.81.3.288

Taylor, F. I., Kenyon, D., and Rosser, S. (2014). Isothiocyanates inhibit fungal pathogens of potato in in vitro assays. Plant Soil 382, 281-289. doi: 10.1007/ s11104-014-2157-y

Viaene, T., Langendries, S., Beirinckx, S., Maes, M., and Goormachtig, S. (2016). Streptomyces as a plant's best friend? FEMS Microbiol. Ecol. 92:119. doi: 10.1093/ femsec/fiw119

Wang, Q., Garrity, G. M., Tiedje, J. M., and Cole, J. R. (2007). Naïve Bayesian classifier for rapid assignment of rRNA sequences into the new bacterial 
taxonomy. Appl. Environ. Microbiol. 73, 5261-5267. doi: 10.1128/aem.00 062-07

Wei, F., Passey, T., and Xu, X. M. (2016). Amplicon-based metabarcoding reveals temporal response of soil microbial community to fumigation-derived products. Appl. Soil Ecol. 103, 83-92. doi: 10.1016/j.apsoil.2016. 03.009

Xu, W. H., Wang, Z. G., and Wu, F. Z. (2015). The effect of D123 wheat as a companion crop on soil enzyme activities, microbial biomass and microbial communities in the rhizosphere of watermelon. Front. Microbiol. 6:899. doi: $10.3389 /$ fmicb. 2015.00899

Yu, X. M., Ai, C. X., Xin, L., and Zhou, G. F. (2011). The siderophore-producing bacterium, Bacillus subtilis CAS15, has a biocontrol effect on Fusarium wilt and promotes the growth of pepper. Eur. J. Soil Biol. 47, 138-145. doi: 10.1016/j. ejsobi.2010.11.001

Zhao, S., Liu, D. Y., Ling, N., Chen, F. D., Fang, W. M., and Shen, Q. R. (2014). Bio-organic fertilizer application significantly reduces the Fusarium oxysporum population and alters the composition of fungi communities of watermelon
Fusarium wilt rhizosphere soil. Biol. Fertil. Soils 50, 765-774. doi: 10.1007/ s00374-014-0898-7

Zhou, J. Z., Xue, K., Xie, J. P., Deng, Y., Wu, L. Y., Cheng, X. L., et al. (2012). Microbial mediation of carbon-cycle feedbacks to climate warming. Nat. Clim. Change 2, 106-110. doi: 10.1038/nclimate1331

Conflict of Interest Statement: The authors declare that the research was conducted in the absence of any commercial or financial relationships that could be construed as a potential conflict of interest.

Copyright (c) 2018 Ren, Ma, Guo, Gentry, Hu, Pierson and Gu. This is an open-access article distributed under the terms of the Creative Commons Attribution License (CC BY). The use, distribution or reproduction in other forums is permitted, provided the original author(s) and the copyright owner are credited and that the original publication in this journal is cited, in accordance with accepted academic practice. No use, distribution or reproduction is permitted which does not comply with these terms. 